Running head: MIND PERCEPTION AND INDIVIDUATION

Perceiving Sophisticated Minds Influences Perceptual Individuation

Steven M. Almaraz ${ }^{1}$, Kurt Hugenberg ${ }^{1}$, \& Steven G. Young ${ }^{2}$

Miami University ${ }^{1} \quad$ Baruch College and The Graduate Center - CUNY ${ }^{2}$

Word Count: 150 (abstract) + 9080 (main body) + 224 (footnotes) + 1373 (references) + 15 (authors' note) $=10842$

Authors' Note:

This research was supported by NSF Grant BCS-1423765, awarded to the second and third authors. 


\begin{abstract}
In six studies, we investigated how ascribing humanlike versus animallike minds to targets influences how easily targets are individuated. Across the studies, participants learned to discriminate amongst a variety of 'aliens' (actually Greebles; Gauthier \& Tarr, 1997). Our initial study showed that participants' ability to learn to individuate targets was related to beliefs that targets had sophisticated minds. Investigating the directionality of this relationship, we found that learning to better recognize the targets did not affect perceptions of mind (Study 2). However, when targets were described as having sophisticated humanlike (relative to simplistic animallike) mental faculties, perceivers indicated more motivation to individuate (Study 3) and were more successful individuating them (Studies 4 \& 5). Finally, we showed that increased self-similarity mediated the relationship between targets' mental sophistication and perceivers' motivation to individuate (Study 6). These findings indicate ascribing sophisticated mental faculties to others has implications for how we individuate them.
\end{abstract}

Keywords: mind perception, individuation, humanity, Greebles 


\section{Perceiving Sophisticated Minds Influences Perceptual Individuation}

Perceiving or withholding sophisticated minds from other organisms is an essential part of human cognition (Dennet, 1996), and has consequences that ramify throughout social judgment. Organisms with sophisticated, humanlike minds are seen as members of the moral community, deserving of individual rights and humane treatment, whereas those without such capacities are seen as existing outside of the moral community and, therefore, subject to ill treatment (Vasiljevic \& Viki, 2013). Indeed, research has demonstrated that believing other humans have sophisticated minds can forestall harmful treatment and can facilitate fairness and empathy (Čehajić, Brown \& Gonzalez, 2009), whereas withholding sophisticated mental capacities from others (e.g., dehumanization) can be both cause and consequence of aggression (Castano \& Giner-Sorolla, 2006; Viki, Osgood, \& Phillips, 2013) and discrimination (Pereira, Vala, \& Leyens, 2009).

In the current research, we seek to extend the effects of mind perception to a new domain: individuation, or the ability to learn to distinguish amongst similar stimuli (see Hugenberg, Young, Bernstein, \& Sacco, 2010 for a review). If ascribing humanlike faculties to organisms is central to believing those organisms have individual rights, this suggests that mind perception may be bound up with perceptual individuation. To what extent does believing an organism has a humanlike mind influence how quickly and easily one can learn to individuate (i.e., discriminate amongst) otherwise similar organisms? Or alternately, to what extent does learning to individuate organisms generate the perception of humanlike minds? Herein, we investigate the question of how individuation is related to mind perception, testing two possibilities. Perhaps targets that are easily individuated are perceived as possessing more humanlike mental capacities (an individuation-to-mind link). Alternatively, the perception of humanlike faculties in targets may motivate perceivers to individuate (a mind-toindividuation link).

These questions of whether beliefs about targets' minds influence or are influenced by the learning and processing of those targets are important for a variety of reasons. First, although an extensive 
literature has emerged on how and when we infer minds, be they sophisticated or simplistic, in other organisms (Epley, Waytz, \& Cacioppo, 2007; Gray, Gray, \& Wegner, 2007; Haslam, 2006), surprisingly little research has investigated how this process of inferring minds influences other basic social cognitive processes, such as perceptual learning or intracategory individuation. Second, the process of discriminating amongst similar targets is commonly understood as the result of expertise mechanisms (e.g., Gauthier \& Tarr, 1997; Tarr \& Gauthier, 2000), however few researchers have investigated how beliefs about stimuli - such as being more or less mentally sophisticated - may influence this process.

To this end, we first briefly discuss the relevant literature on mind perception before turning to a discussion of how perceivers learn to individuate. We then present six studies investigating the relationship between individuation and mind perception. In Study 1, we demonstrate that perceiving organisms to have sophisticated minds and learning to individuate them are correlated. We then demonstrate that, whereas learning to individuate does not generate the belief that an organism has a sophisticated mind (Study 2), believing organisms have sophisticated minds can influence perceivers' motivation to individuate (Study 3) and individuation performance (Studies 4 and 5). Finally, we show that the effects of humanlike faculties on the motivation to individuate are mediated by perceptions of similarity to the self (Study 6). Across the studies, it appears that perceivers are motivated to learn the unique identities of humanlike organisms because of their similarity to the self.

\section{Perceiving Humanlike and Animallike Minds}

A lengthy review of the various theories of mind perception and similar constructs is beyond the scope of the current work (see Waytz, Epley, \& Caccioppo, 2010 for a review). However, there is some consistency in how scholars from multiple research traditions - including the infrahumanization (Leyens et al., 2000; Leyens, Demoulin, Vaes, Gaunt, \& Paladino, 2007), dehumanization (Haslam, 2006; Haslam \& Loughnan, 2014), objectification (Loughnan, Haslam, \& Bastian, 2010), and mind perception (Waytz, Gray, Epley, \& Wegner, 2010) literatures - explain ascriptions of humanity (see Vaes, Bain, \& Leyens, 2014 for a review). Many prominent perspectives focus on how humans are seen as possessing sophisticated capacities that are distinct from other animals, while having an experiential capacity that 
makes humans distinct from inanimate objects, such as machines and automata (see Haslam \& Loughnan, 2014).

Non-human animals, such as dogs and frogs, are seen as able to experience the world and simple emotional states, but have limited cognitive and agentic abilities; whereas non-human agents, such as robots, are seen as able to cogitate and act upon the world, but lacking in inner experience (Gray et al., 2007). Only (adult) humans are seen as having sophisticated experiential and agentic capacities. Notably, these ascriptions of humanlike capacities to others are malleable, depending on various perceiver characteristics and motives (Epley et al., 2007; Waytz et al., 2010). For example, when targets become likeable, when perceivers desire predictive capacity, or when perceivers come to desire a sense of control or social connection, a vast variety of targets (ranging from machines to animals) are more likely to be seen as humanlike (see Epley et al., 2007; Epley, Akalis, Waytz, \& Caccioppo, 2008). Relatedly, when perceivers become motivated to derogate or distance themselves from social outgroups, due to intergroup conflict (e.g., Castano \& Giner-Sorolla, 2006; Cortes, Demoulin, Rodriguez, Rodriguez, \& Leyens, 2005) or status differences (e.g., Leyens et al., 2001, 2007), full humanity is withheld. Conversely, when outgroups become relevant and interdependent with ingroups (e.g., Capozza, Falvo, Favara, \& Trifiletti, 2013; see also Leyens et al., 2007 for a review), or when an individual becomes interdependent on another individual (Khalid, Deska, \& Hugenberg, 2016), others are more likely seen as possessing fully human capacities.

One of the established sequelae of ascribing a humanlike mind to a target is to experience it as unique and individuated, whereas one of the potential consequences of withholding a mind from an organism is to see it as fungible and interchangeable with other members of the group. This question of uniqueness versus fungibility is central to multiple definitions of humanness and multiple models of dehumanization (e.g., Haslam, 2006; Nussbaum, 1999). Given our focus in the current work on how ascribing targets humanlike minds (or not) may influence or be influenced by perceivers' ability to learn the differences amongst targets, the issue of uniqueness versus fungibility is key. Put simply, perhaps an anthropomorphic mind makes a target seem unique and changes how that organism is processed and 
remembered, whereas believing a target is fungible or interchangeable with others of its kind (because of the lack of a humanlike mind) makes people less motivated to learn the perceptual details that distinguish it from its peers. Alternatively, the ease with which people are able to individuate others may make them seem more individual and more humanlike in mind.

\section{Individuating Exemplars}

In the psychological literature, the term individuation has been used in two distinct ways. In its original use, individuation denoted processing a person deeply and without stereotypes (e.g., Fiske \& Neuberg, 1990), a meaning still in active use in the stereotyping literature (e.g., Claypool \& Bernstein, 2014). More recently, researchers have also used the term individuation to mean the capacity to perceptually discriminate amongst similar stimuli (especially in the literature on face perception; e.g., Hugenberg et al., 2010; Mason \& Macrae, 2004). Here, we use the latter sense of the term. To what extent does believing a target has a humanlike mind make it more distinguishable from similar targets, or to what extent does being able to distinguish between organisms lead perceivers to ascribe humanlike characteristics to them?

As previously noted, the ability to individuate stimuli is the result of perceptual expertise with targets. Expertise with a class of stimuli (e.g., cars, faces) facilitates identification for targets of that expertise (e.g., Curby \& Gauthier, 2009; Tanaka, 2001). Part of the process of attaining expertise individuating stimuli is gaining an increasing ability to make sophisticated perceptual judgments of stimuli, including subordinate-level recognition and identity recognition, quickly and accurately (e.g., Scott, Tanaka, Sheinberg, \& Curran, 2008). However, building this expertise is not free - it can require extensive and effortful training in the domain of interest (e.g., Gauthier \& Tarr, 1997).

In the current work, we investigate the relationship between individuation and mind perception by employing specialized stimuli - Greebles - that are designed to have a variety of unique, individuating characteristics, and yet to be generally perceptually similar to one another. Just as all human faces have eyes, noses, and mouths, yet the constellation of these features creates the variegated facial identities we see everyday, all Greebles (see Figure 1) have 'boges,' 'quiffs,' and 'dunths,' the lengths, shapes, and 
orientations of which can be used to tell each Greeble apart. These similarities to human faces are not happenstance; Greebles were originally pioneered by Gauthier and Tarr (1997) to investigate how increasing expertise with stimuli may influence face-like individuation processes. Indeed, one problem with manipulating individuation expertise with human faces is that, by the time adult participants arrive in a laboratory, they have a lifetime of expertise individuating faces (Tanaka, 2001). Instead, by constructing face-like stimuli, one can manipulate expertise within the laboratory.

In the basic procedure (see Gauthier \& Tarr, 1997), participants are exposed to a variety of Greebles that share many similarities (a ‘family’ of Greebles, in Gauthier and Tarr's original instructions), but that are subtly different from one another. One Greeble may have distinctively long Boges, whereas another may have a sharper Quiff and Dunth than others (see Figure 1). Each Greeble is presented along with a list of possible names, then participants begin guessing the names of the Greebles. Over dozens of trials, participants learn to associate each name with a particular unique Greeble. Of interest in the basic paradigm is whether participants can learn to process Greebles over time and, once they do, whether they are using mechanisms typically reserved for individuating human faces. Although Greebles are not processed identically to human faces, after experience individuating Greebles is gained, they do share key features of human face processing, such as being susceptible to inversion effects (e.g., Gauthier \& Tarr, 1997) and being able to activate so-called 'face-specific' areas of the brain (Gauther, Tarr, Anderson, Skudlarski, \& Gore, 1999; Tarr \& Gauthier, 2000), which makes them valuable for understanding how mind perception may influence individuation.

In our case, using Greebles to understand how mind perception may be related to individuation has a number of advantages. First, just like Gauthier and Tarr's (1997) initial intent, Greebles are facelike but without a lifetime of prior expertise, which allows us insight into how perceivers' beliefs about minds and ability to individuate develop alongside each other; processes that would be obscured if we attempted to understand individuation with human faces (with which perceivers have extensive preexisting expertise). Second, using humanlike stimuli, rather than actual human faces, makes the overt manipulation of beliefs about the stimuli more plausible - it would be difficult to show participants a set 
of human faces and tell them these persons have only animallike faculties, or to show them blue jays and convince them these foul have fairly humanlike faculties. Indeed, recent research shows that the mere presence of upright human faces can be sufficient for the spontaneous inference of humanlike capacities (Deska, Almaraz, \& Hugenberg, 2017; Hugenberg et al., 2016; see also Looser \& Wheatley, 2010). Third, using Greebles allows us to eliminate other associations that might occur for actual human faces, such as physical attractiveness effects and stereotypes about race, gender, or other visually marked social cues. Finally, the use of non-human stimuli to investigate mind perception is squarely in the recent tradition in mind perception research illustrating that, under certain conditions, humanlike traits are projected onto a range of non-human stimuli (e.g., Epley et al., 2007; Waytz, Heafner, \& Epley, 2014).

\section{Current Research}

We tested two primary hypotheses concerning the relationship between mind perception and individuation. The first hypothesis was that perceivers may impute more humanlike faculties to novel organisms after learning to individuate them. The second (and not necessarily mutually exclusive) hypothesis was that perceivers may learn to individuate novel organisms believed to have humanlike minds more quickly than organisms believed to be unsophisticated and animalistic. Further, we also sought preliminary evidence for a mechanism by which mind perception and individuation may be linked.

\section{Study 1}

Study 1 was designed as an exploratory test of the relationship between individuation and mind ascriptions. Here, we simply sought to investigate whether participants who spontaneously ascribed more sophisticated minds to a novel alien species (Greebles) were more successful in individuating members of this species. In this study, participants were instructed to imagine they were anthropologists landing on an alien planet, and were encountering a species for the first time. Their task was to learn to differentiate between members of this new species and to consider the way this species might live, including how they interact with each other and the world around them, to pick up on their likely characteristics. Participants thus completed a set of 100 trials in which they learned to discriminate amongst five exemplars of the 
new species, named Greebles, before rating the species on 12 characteristics representing Agency (e.g., consciousness, planning, and morality) and Experience (e.g., desire, pride, and pleasure).

This design allows us to answer the initial question in this line of work: is individuation ability related to perceived dimensions of mind? If either of our hypotheses were true, we would expect individuation skill to correlate positively with perceptions of mind.

\section{Methods}

Participants. Because work relating individuation skill to humanity in non-human stimuli is completely novel, we had no a priori effect size to work from. Thus, we targeted 80 participants, which would give us more than $80 \%$ power to detect moderate effect sizes $(r=.3)$. In actuality, eighty-four undergraduates $\left(M_{\mathrm{age}}=18.68, S D=1.51\right)$ participated in this study for partial course credit. Most participants were White $(84.5 \%)$ and female $(57.1 \%)$. No participants performed below chance levels on the individuation task, and thus none were removed from analyses.

Stimuli. We employed Gauthier and Tarr's (1997) Greebles as stimuli in the current work. As described above, Greebles are three-dimensional objects, which like faces, have a small number of appendages in a common configuration. Each Greeble consists of a segmented body with four appendages: two boges, a quiff, and a dunth (see Figure 1). Together, these features can be used to distinguish each individual Greeble.

In Study 1, we employed one 'family' of five Greebles (see Gauthier \& Tarr, 1997). Each family of Greebles shares intra-family similarities amongst the members of that family (i.e., having similar colors and body shapes), but differ in the details of their boges, quiffs, and dunths. Stimuli were displayed on $360 \times 320$ pixel white rectangles. 

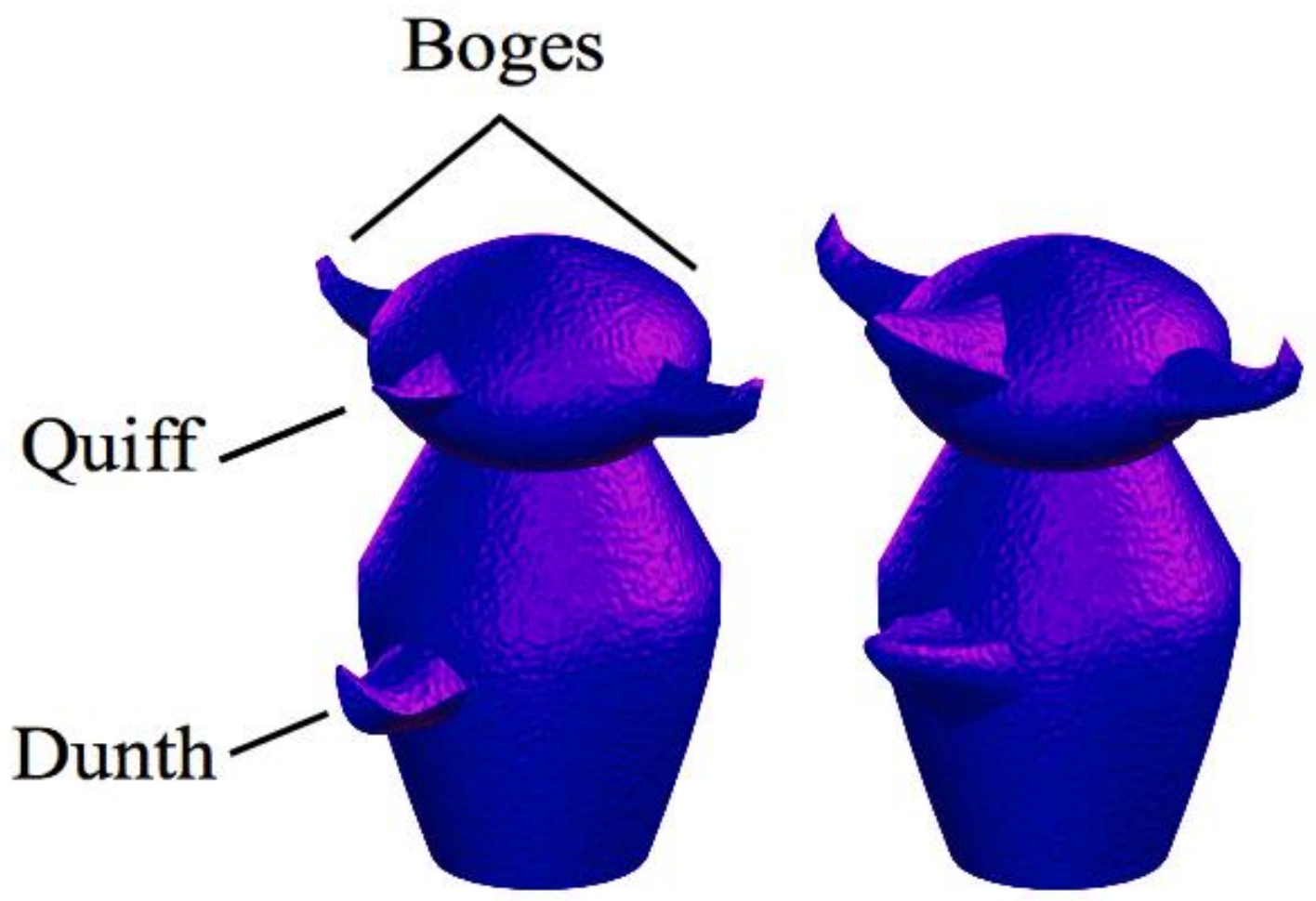

Figure 1. Greebles used in this study had this configuration of two boges, a quiff, and a dunth. Shown are two members of the same Greeble 'family'. As such, they share a common color and body shape, but vary in the shapes and sizes of their appendages.

Procedure. In this study, participants read a cover story that introduced them to a group of Greebles. Participants then learned to individuate these stimuli, and finally rated this species on characteristics related to Agency and Experience (Gray et al., 2007).

Participants performed all tasks in a private computer cubicle. After providing informed consent, participants were told to imagine they were anthropologists on an alien planet (see Appendix A). They were informed this study would focus on one newly discovered species native to the planet: the Greebles. Their task was to learn to discriminate amongst members of the new species. After reading these instructions, participants completed the Individuation Task. 
The Individuation Task, adapted closely from Gauthier and Tarr (2002), began with the presentation of the 5 members of the target species, one at a time, along with each exemplar's assigned letter (A, B, C, D, or E). Letters were used as name-like signifiers in this task because we thought letters less likely to signal humanness than other signifiers (e.g., naming the stimuli Amanda, Bob, Cathy, etc.). After seeing each stimulus paired with a letter, the training was completed in five blocks of 20 trials. On each trial, a stimulus was presented along with the letters for each individual (A through E), and participants were tasked with accurately selecting the correct letter for that target via keystroke. After each response, participants were given immediate feedback about whether their response was correct and, if not, which letter was correct. Each of the 5 exemplars was shown four times per 20-trial learning block in a random order. Between each 20-trial block, participants took a short, self-paced break.

Once all 100 trials of the Individuation Task were completed, participants began the mind ascription portion of the study, rating the new species on the extent to which it had the mind dimensions of Agency and Experience (Gray et al., 2007). Traits related to Agency included memory, self-control, planning, emotion recognition, morality, and communication, whereas traits related to Experience included hunger, pride, pleasure, desire, consciousness, and personality. For each trait, presented one at a time in a randomized order, participants rated "to what extent do you believe Greebles have" that capacity. Participants rated the species on each trait, using a seven-point Likert scale, with 1 being "Not at all" and 7 being "Very much."

After completing both the Greeble individuation and the trait-rating measures, participants completed a demographics questionnaire and were thanked and debriefed.

\section{Results and Discussion}

The current study was designed to test whether perceptions of a new species' minds were related to perceivers' ability to individuate that species. That is, do people who are better able to differentiate between the exemplars of a new species perceive that species as having more sophisticated minds? To test this possibility, an accuracy score across all trials was calculated for each participant indexing each participant's ability to individuate the stimuli, and separate mean ratings for Agency and Experience were 
calculated for each participant. If either ascribing humanlike minds to face-like objects leads to an increased ability to learn to recognize those objects (hypothesis 1) or learning to individuate between face-like objects leads to increased ascriptions of humanlike (containing both Agency and Experience) minds (hypothesis 2), we would expect to see that participants who were better at individuating Greebles also ascribed more Agency and Experience to those Greebles.

As expected, Agency $(\alpha=.874)$ and Experience $(\alpha=.873)$ were strongly correlated with one another, $r(82)=.863, p<.001$, and were therefore averaged into a single dimension of humanlike mind. Further, and consistent with our hypotheses, overall accuracy individuating Greebles was correlated with ratings of Greebles having a humanlike mind, $r(84)=.269, p=.013$. Separate correlations between individuation accuracy and Agency, $r(84)=.258, p=.018$, and Experience, $r(84)=.262, p=.016$, demonstrate similar results. This provided initial evidence of a relationship between the ability to individuate novel organisms and the belief that these organisms have more humanlike minds. ${ }^{1}$

\section{Study 2}

Although Study 1 provided evidence for a relationship between perceptions of mind and individuation skill, the causal direction of this relationship cannot be determined. Study 2 sought to investigate the possibility that learning to effectively individuate novel stimuli causes perceptions of sophisticated minds (Hypothesis 1). To accomplish this goal, we used a procedure similar to Study 1, but added pretest measures of targets' Agency and Experience for half of the participants; the other half of the participants completed only post-test measures of Agency and Experience, exactly as in Study 1.

We expected to replicate Study 1, showing that perceptions of Greebles' minds would be related to participants' ability to individuate them. Also, if the individuation-to-mind directional hypothesis were true, we would expect to observe a number of possible outcomes. First, if learning to individuate causes

\footnotetext{
${ }^{1}$ Though not central to the goals of this paper, we also tested participants' individuation performance and learning across blocks. A repeated-measures ANOVA revealed a significant main effect of Block, $F(4,332)=144.000, p<.001, \eta_{p}^{2}=0.634$, and significant linear, $F(1,83)=262.768, p<.001, \eta_{p}^{2}=0.760$, and quadratic trends, $F(1,83)=76.677, p<.001, \eta_{p}^{2}=0.480$, which demonstrate both that learning occurred, and that early gains in learning tapered for later blocks. Notably, Block 5 accuracy $(M=0.942, S D=0.112)$ was significantly different from ceiling, $t(83)=-4.767, p<.001$.
} 
more humanlike minds, a difference between pretest and posttest ratings in the Pretest-Posttest condition should occur (i.e., a within-subjects test in the Pretest-Posttest condition). Although this prediction is straightforward, we also allowed the possibility that there may be stability effects in the ratings from pretest to posttest in the Pretest-Posttest condition (i.e., participants may remember their previous ratings of Greebles' minds and be hesitant to change them at posttest). The current design also allows for the between-subjects comparison of the pretest ratings in the Pretest-Posttest condition to the posttest ratings in the Posttest Only condition. Thus, even in the presence of stability effects, we may observe that individuation training can cause an increase in ascriptions of humanlike minds on a between-subjects basis.

\section{Methods}

Participants. Because one of the goals of this study was to replicate the previous study, we targeted a sample size similar to Study 1 . After running to the end of one semester, only 58 participants had been collected, and a $\mathrm{G}^{*}$ Power post hoc power analysis revealed that, as was predicted based on the a priori criterion, the critical analysis was under-powered. Thus, a second wave of participants was collected in the subsequent semester. In total, 99 undergraduates participated in this study for partial course credit. Two participants who were unable to finish the study and one participant who performed below chance in the individuation task were excluded from analyses, leaving 96 participants $\left(M_{\mathrm{age}}=19.01\right.$, $S D=2.64)$ for analysis. Most participants were White $(83.3 \%)$ and female $(58.3 \%)$. The pattern of results remained nearly identical across participant waves, with the critical effects being significant both when analyzed using only the wave 1 partial sample or the full sample.

Stimuli. The stimuli used in Study 2 were exactly the same as those of Study 1.

Procedure. The goal of Study 2 was to determine whether learning to individuate Greebles influenced perceptions of their humanlike faculties. To accomplish this, we used a procedure nearly identical to that of Study 1, except that half of participants made ratings of Agency and Experience for the Greebles before performing the individuation task, and then again after the individuation task (PretestPosttest condition). 
Thus, all participants first read a cover story introducing them to Greebles. Before moving to the Individuation Task (identical to Study 1), half of the participants rated the Greebles on dimensions of Agency and Experience. All participants then completed the Individuation Task and rated Greebles on Agency and Experience.

\section{Results and Discussion}

Study 2 intended to replicate the findings of Study 1 and to investigate whether the act of learning to individuate Greebles affected participants' ratings of Greebles' minds.

Preliminary Analyses. The Posttest Only condition provides an exact replication of Study 1, so we first analyzed these data to ensure replication of the previous findings. In the Posttest Only condition, Agency $(\alpha=.904)$ and Experience $(\alpha=.895)$ were very strongly correlated, $r(45)=.930, p<.001$, and were again averaged to provide a single index of humanlike faculties. Consistent with the results of Study 1, participants' individuation accuracy was correlated with perceiving Greebles as having humanlike faculties, $r(45)=.396, p=.006$. Analyzed separately, individuation accuracy was positively correlated with both Experience, $r(45)=.412, p=.004$, and Agency, $r(45)=.365, p=.012$.

Primary Analyses. Of primary interest was whether individuation skill would lead to ascriptions of humanlike minds (hypothesis 1). If participants ascribe more humanlike minds to Greebles after they have learned to individuate them, we would expect to find either a within-subjects increase in ratings of sophisticated minds between pretest and posttest measures (using only the Pretest-Posttest Condition) or a between-subjects difference between pretest ratings (in the Pretest-Posttest condition) and posttest ratings (in the Posttest Only condition). In essence, if learning to individuate leads to the perception of a sophisticated mind, we should see ratings of sophisticated minds increase after training.

A paired-samples t-test found no observable difference between pretest $(M=3.959, S D=1.082)$ and posttest $(M=4.104, S D=1.250)$ ratings of Greebles' minds in the Pretest-Posttest Condition, $t(48)=-$ $1.182, p=.243, d=-0.124$. Analyzing Agency $\left(\alpha_{\text {pre }}=.791 ; \alpha_{\text {post }}=.896\right)$ and Experience $\left(\alpha_{\text {pre }}=.843 ; \alpha_{\text {post }}=.865\right)$ separately, we found that for neither Agency, $t(48)=-0.571, p=.570, d=-0.069$, nor Experience, $t(48)=-$ $1.567, p=.124, d=-0.163$, were there any significant differences between pretest $\left(M_{\text {agency }}=3.803\right.$, 
$\left.S D_{\text {agency }}=1.070, M_{\text {experience }}=4.116, S D_{\text {experience }}=1.244\right)$ and posttest $\left(M_{\text {agency }}=3.884, S D_{\text {agency }}=1.309\right.$,

$\left.M_{\text {experience }}=4.323, S D_{\text {experience }}=1.291\right)$.

The current design also allows for the comparison between pretest and posttest ratings on a between-subjects basis as well. Support for the individuation-to-mind hypothesis would be observed as higher ratings in the posttest (in the Posttest Only condition) relative to the pretest (in the Pretest-Posttest Condition). An independent-samples t-test indicates that posttest ratings (absent pretest measures; $M=2.966, S D=1.325)$ were significantly lower than pretest ratings $(M=3.959, S D=1.082), t(94)=-4.029$, $p<.001, d=-0.821$, in direct contravention of the individuation-to-mind hypothesis. Analyzing Agency and Experience separately, we found that ratings in the Posttest Only condition $\left(M_{\text {agency }}=2.897, S D_{\text {agency }}=1.347\right.$, $M_{\text {experience }}=3.035, S D_{\text {experience }}=1.351$, were significantly lower on both Agency, $t(94)=-3.655, p<.001, d=-$ 0.745, and Experience, $t(94)=-4.077, p<.001, d=-0.832$, compared to pretest ratings $\left(M_{\text {agency }}=3.803\right.$, $\left.S D_{\text {agency }}=1.070, M_{\text {experience }}=4.115, S D_{\text {experience }}=1.244\right)$.

Not only did the within-subjects analyses fail to provide support for the purported individuationto-mind link, the between-subjects analysis provides evidence to the contrary: participants who were randomly assigned to rate Greebles after training ascribed them less sophisticated faculties than did participants who rated Greebles before training.

Ancillary Analysis: Were there learning differences between the conditions? To compare the pretest and posttest ratings between-subjects, it is important to know whether there were learning differences between-subjects (i.e., were there group level differences in their ability to learn faces?). As such, we conducted a 2 (Condition: Pretest-Posttest vs. Posttest Only) x 5 (Block) mixed-measures ANOVA, with repeated-measures on Block. The ANOVA yielded only a significant main effect of Block, such that participants were significantly better at differentiating between Greebles during later Blocks than during earlier Blocks (i.e., learning occurred), $F(4,376)=120.492, p<.001, \eta_{p}^{2}=0.562$. Neither the 
main effect of Condition, $F(1,94)=0.639, p=.426, \eta_{p}^{2}=0.007$, nor the interaction of Condition and Block, $F(4,376)=1.064, p=.374, \eta_{p}^{2}=0.011$, approached significance. ${ }^{2}$

\section{Study 3}

Whereas Study 2 found evidence that is not congenial with an individuation-to-mind link, Study 3 investigated the opposite putative causal pattern: that creating the perception of sophisticated versus unsophisticated minds can motivate individuation. In line with this possibility, we predicted that perceivers would be more motivated to individuate organisms they believe have humanlike minds, relative to organisms that have more animallike faculties. Indeed, past research on face and person perception has demonstrated that the motivation to visually discriminate between a class of stimuli (e.g., a class of faces) can lead perceivers to more easily learn the difference between them (e.g., Hugenberg et al., 2010; Pauker, Weisbuch, Ambady, Sommers, \& Ivcevic, 2009; Young \& Hugenberg, 2012).

To investigate whether the perception of sophisticated and unsophisticated minds influences the motivation to individuate, participants received information about two new alien species, one with sophisticated humanlike characteristics and one with unsophisticated animallike characteristics, and reported their motivation to learn to individuate members of these species.

\section{Methods}

Participants. An a priori power analysis using the effect size from Study 1 indicated a target $\mathrm{N}=28$. In actuality, 51 mTurk workers $(70.6 \%$ White; $64.7 \%$ female) completed this study for $\$ 0.50$ $\left(M_{\mathrm{age}}=35.69, S D=14.08\right)$.

Stimuli and Procedure. The purpose of Study 3 was to test whether ascriptions of humanlike versus animallike minds to novel organisms affect participants' motivation to individuate. To accomplish this, we adapted the 'alien anthropologist' cover story from the procedure of Study 1. Participants were told to imagine they were anthropologists on an alien world, where they encountered two new species

${ }^{2}$ The ANOVA yielded only significant linear and quadratic contrasts for Block, such that participants were significantly better at differentiating between Greebles during later Blocks than during earlier Blocks (i.e., learning occurred), $F(1,94)=233.444, p<.001, \eta_{p}^{2}=0.713$, and learning increases were steeper for early blocks than late blocks, $F(1,94)=38.404, p<.001, \eta_{p}^{2}=0.290$. 
native to the planet: 'Greebles' and 'Animodes.' Participants then read a short description of each species (see supplemental online materials). 'Greebles' were described as having sophisticated human faculties, advanced math and science, intricate social structures, and sophisticated inner states. 'Animodes' were described as mentally unsophisticated herd animals and occasional pets of the Greebles, with little cognitive complexity. After reading these descriptions, all participants were asked to indicate the extent to which they "would be interested in learning the unique identities of" the humanlike 'Greebles' and the animallike 'Animodes' on a 1 (Completely Uninterested) to 7 (Extremely Interested) Likert scale. Finally, participants answered a single question manipulation check, in which they indicated which was the more advanced species ${ }^{3}$, completed a demographics questionnaire, and were thanked and debriefed.

\section{Results and Discussion}

A paired-samples t-test revealed that participants reported significantly more interest in individuating humanlike Greebles $(M=5.73, S D=1.313)$ than the animallike Animodes $(M=4.75$, $S D=1.776), t(50)=3.527, p=.001, d=0.627$. These results provide preliminary support for the mind-toindividuation hypothesis.

\section{Study 4}

Study 3 found that participants report more motivation to individuate Greebles described as more mentally sophisticated, compared with their less sophisticated counterparts. In Study 4, we aimed to investigate whether targets' mental sophistication actually influences individuation performance. In Study 4, we employed a between-subjects manipulation of targets' mental sophistication (similar to Study 3), paired with the individuation task in Studies 1 and 2. Of interest is whether believing an organism has humanlike faculties (versus animallike faculties) actually influences perceivers' ability to learn to individuate those targets.

\section{Methods}

\footnotetext{
${ }^{3}$ Six participants failed the manipulation check. Excluding these participants does not change the overall pattern of results, and the humanlike advantage is descriptively larger when these participants are excluded.
} 
Participants. An a priori power analysis using the effect size from Study $1(r=.27, d=0.56)$ for two between-subjects conditions indicates a target $\mathrm{N}$ of 104 participants. In actuality, 106 undergraduates participated for partial course credit. Five participants were unable to complete the study and were thus eliminated, leaving a final sample of $101\left(M_{\text {age }}=18.85, S D=2.15 ; 87.1 \%\right.$ White; $54.5 \%$ male $)$. No participants performed below chance on the individuation tasks.

Stimuli. In the current work we employed two separate 'families' of Greebles, with 5 Greebles per family. One family was colored red and the other blue, and there were intra-family similarities amongst the Greebles of a given family and also inter-family differences (e.g., red Greebles all had relatively sharper dunths relative to blue Greebles). One 'family' of Greebles was used in a familiarization task (Practice Phase) and the other family was used as the target stimuli during the critical learning task (Testing Phase; see below). This was done to give participants impressions of two separate sets of stimuli, one of which was used to familiarize participants with the stimuli, and the other which was used for the actual learning phase. Which 'family' of Greebles was used during each task was counterbalanced. All stimuli were displayed on a 360x320 pixel white rectangle.

Procedure. The purpose of Study 4 was to test whether ascriptions of humanlike versus animallike minds to novel organisms affects individuation. To accomplish this, we adapted the procedure of Study 1. In this new procedure, participants completed three stages. First participants completed a practice learning task involving one 'family' of Greeble stimuli (Practice Phase), designed to give participants practice with the task and the stimuli. In the second stage, all participants were then given the 'alien anthropologist' instructions, and were randomly assigned to learn about either a species with humanlike or animallike faculties. In the third stage, all participants then completed an individuation task identical to the previous studies (Testing Phase).

After completing informed consent, participants were instructed that they would complete an experiment involving the learning of new shapes and new species. Participants were first instructed that they were going to learn to identify new 3-dimensional shapes. In actuality, this was a Greeble learning task nearly identical to that of the previous studies, but was described as a shape-learning task. This was 
designed to give participants practice with the critical task. Stimuli were labeled with numbers, and participants learned to pair the correct stimulus with the correct number over the course of 5 blocks of 20 trials (100 total trials).

After completing this Practice Phase, participants were given the same alien anthropology manipulation used in Study 3, presented with examples of each species. Again, 'Greebles' were described as beings with humanlike faculties, whereas 'Animodes' were described as having animallike faculties. After reading these descriptions, participants were randomly assigned to be instructed that the species they were about to learn were the humanlike 'Greebles' or the animallike 'Animodes.' In actuality, there were no differences between the stimuli used for humanlike and animallike conditions. Participants simply completed a learning task for the remaining set of stimuli that was not used previously. Notably, participants did not learn to individuate both species; species was a between-subjects manipulation. As in the Practice Phase, participants completed 5 blocks of 20 trials (100 total trials) in the Testing Phase.

Lastly, participants provided demographic information and were thanked and debriefed.

\section{Results and Discussion}

The focus of Study 4 was to investigate whether organisms with humanlike mental capacities were better individuated than those with animallike minds. If so, we would expect better individuation of the same stimuli described as having humanlike versus animallike mental faculties. We first computed mean accuracy scores in both the Practice Phase and the Testing Phase (Humanlike vs. Animallike faculties).

Accuracy scores were submitted to a 2 (Learning Phase: Practice v. Testing) x 2 (Species: Humanlike v. Animallike Faculties) mixed-model ANOVA, with repeated-measures for Learning Phase. The ANOVA revealed a significant main effect of Species, $F(1,99)=5.389, p=.022, \eta_{p}^{2}=0.052$, such that those in the Humanlike condition $(M=0.819, S D=0.170)$ had better accuracy scores than those in the Animallike condition $(M=0.732, S D=0.205)$. This was qualified by the predicted interaction between Learning Phase and Species, $F(1,99)=5.561, p=.020, \eta_{p}^{2}=0.053$. As seen in Figure 2 , whereas there was 
no significant between-subjects difference between the two groups in the Practice Phase, $t(99)=-1.114$, $p=.268, d=-0.222$, the ANOVA did yield a difference in accuracy scores between stimuli described as having humanlike faculties $(M=0.858, S D=0.200)$ and those described as having animallike faculties $(M=0.725, S D=0.268), t(99)=-2.824, p=.006, d=-0.563 .^{4}$

The results of Study 4 provide direct support for the putative mind-to-individuation directional hypothesis. Building on the results of Study 3, which showed targets' sophistication influenced perceivers' motivation to individuate, in Study 4, we demonstrate that direct manipulations of targets' sophistication actually influence perceptual individuation. Participants in the Humanlike faculties condition showed better individuation performance than participants in the Animallike faculties condition. Notably, this is not due to differential latent perceptual abilities across the conditions - participants showed equivalent individuation performance in the Practice Phase.

\footnotetext{
${ }^{4}$ Alternate analyses were conducted with Learning Block (1 through 5) as an additional within-subjects factor. This analysis yielded a robust main effect of Block indicative of learning, $F(4,396)=128.190$, $p<.001, \eta_{p}^{2}=0.564$, but the three way interaction between Learning Phase, Species, and Block did not approach significance, $F(4,396)=0.189, p=.944, \eta_{p}^{2}=0.002$.
} 


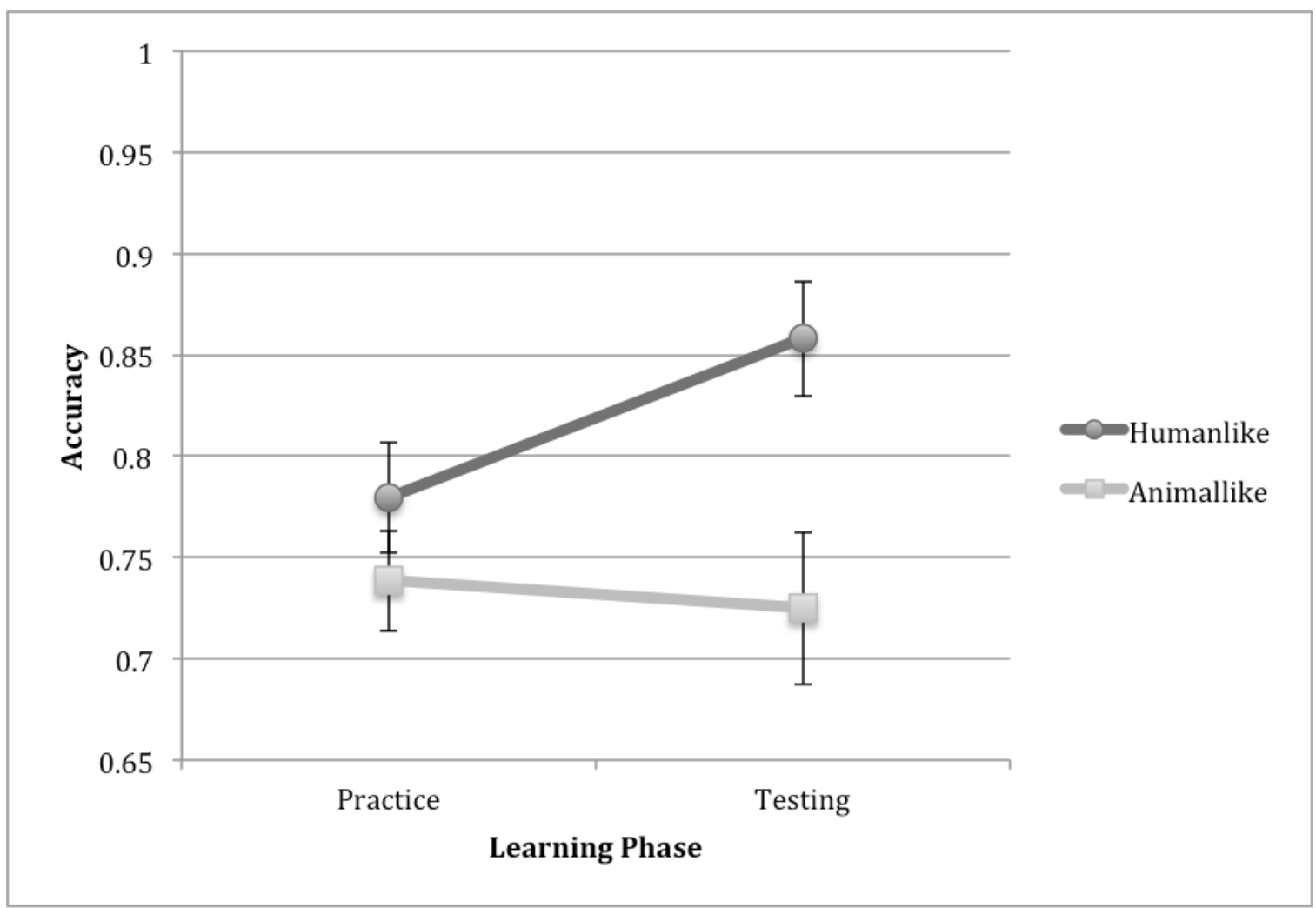

Figure 2. Study 4 Learning Phase x Species interaction. Whereas both groups performed equivalently in the initial Practice Phase, stimuli described as having humanlike faculties were learned better than stimuli described as having animallike faculties in the subsequent Testing Phase.

\section{Study 5}

Study 4 provided direct support for the proposed mind-to-individuation link - believing targets to have humanlike minds facilitates perceivers' ability to tell them apart. However, our design of Study 4 included a novel methodological component: a Practice Phase. Originally, this was designed to give participants practice with the task, while also providing the dual advantages of allowing us to both ensure the humanlike and animallike conditions did not differ in baseline individuation ability (they did not), and of allowing us to control for between-individual differences in baseline ability to distinguish between the stimuli. However, the introduction of this practice phase makes the necessary and sufficient conditions for 
the effects observed in Study 4 ambiguous. Does the effect of targets' mental sophistication on individuation occur only in the presence of some experience with the stimuli?

There may be good reason to believe that the effects of Study 4 may indeed result from a generalization of learning. Perceptual experience with a class of stimuli plays an important role in our ability to perceptually discriminate amongst them (Curby \& Gauthier, 2009; Tanaka, 2001). Recent research in face perception indicates that the ability to individuate novel faces may be the result of participants being willing to extend their prior expertise to novel stimuli only when sufficiently motivated to do so (e.g., Hugenberg, Miller, \& Claypool, 2007; Pauker et al., 2009; Young \& Hugenberg, 2012; see Hugenberg et al., 2010 for a review). Thus, the design of Study 4 leaves open the possibility that humanlike stimuli are more effectively individuated because participants were successful at generalizing their prior experience from the Practice Phase.

Thus, in Study 5, we manipulated the presence versus absence of the Practice Phase prior to learning to individuate humanlike or animallike Greebles. Participants in the Practice Present condition completed the exact same procedure as that of Study 4. Participants in the Practice Absent condition, however, completed the same procedure as in Study 4, but without the Practice Phase. Instead, they immediately began with the 'alien anthropology' cover story, the manipulation of targets' humanlike versus animallike faculties, and the individuation training.

\section{Methods}

Participants. Using the effect size attained in Study 4, an a priori G*Power power analysis suggested a sample size of 120 participants. In actuality, 138 undergraduates $\left(M_{\mathrm{age}}=18.86, S D=0.94\right)$ participated in this study for partial course credit. Most of the participants in this study identified as White (78.3\%) and female (59.4\%). All participants performed above chance levels and thus, no participants were eliminated from analysis.

Stimuli. The stimuli used in Study 5 were the same as those used in study 4 .

Procedure. The procedure of Study 5 is identical to that of Study 4 except as follows. We manipulated between-subjects the presence or absence of a Practice Phase before the critical trials 
measuring individuation of the targets described as having humanlike versus animallike mental capacities. Participants randomly assigned to the Practice Present condition completed the exact procedure of Study 4. Participants in the Practice Absent condition did not perform the Practice Phase (from Study 4).

\section{Results and Discussion}

Of interest in the current study was whether the individuation advantage for humanlike stimuli observed in Study 4 would obtain in the Practice Present condition, and whether this humanlike advantage would obtain or be eliminated in the Practice Absent condition.

Accuracy scores were calculated separately across conditions and submitted to a 2(Condition: Practice Present vs. Practice Absent) x 2(Species: Humanlike vs. Animallike Faculties) ANOVA. The ANOVA revealed no main effects of either Condition, $F(1,134)=0.268, p=.606, \eta_{p}^{2}=0.002$, or Species, $F(1,134)=0.352, p=.554, \eta_{p}^{2}=0.003$, but did reveal a significant interaction between Condition and Species, $F(1,134)=6.136, p=.014, \eta_{p}^{2}=0.044$. As seen in Figure 3, the individuation advantage for stimuli with humanlike faculties $(M=0.905, S D=0.117)$ relative to animallike faculties $(M=0.824, S D=0.212)$ was observed in the Practice Present condition, $t(67)=1.965, p=.054, d=0.473$, but this humanlike advantage was eliminated in the Practice Absent condition, $t(67)=-1.509, p=.136, d=0.363$. 


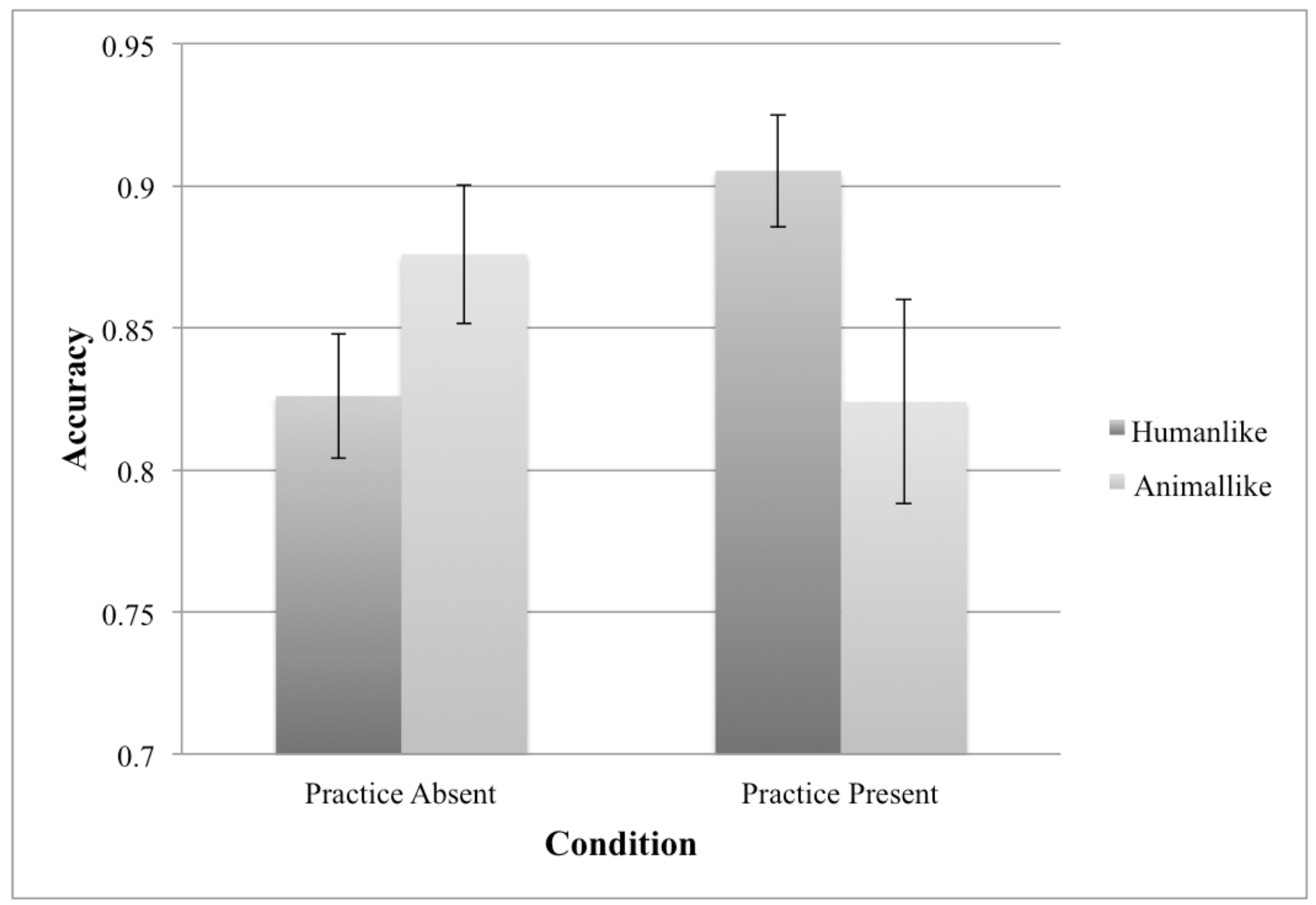

Figure 3. Study 5 Condition x Species interaction demonstrates that the humanlike individuation advantage requires prior practice with similar stimuli.

These findings both replicate and clarify the findings of the previous study. Targets with sophisticated, humanlike mental capacities are more effectively individuated, and this individuation advantage appears to be the result of the generalization of prior individuation experience. Only perceivers with some prior facility in processing similar stimuli showed the humanlike individuation advantage.

\section{Study 6}

The origin of our hypotheses about the link between individuation and mind perception stemmed from classic definitions of dehumanization making others' seem interchangeable (e.g., Nussbaum, 1996). However, this literature is mute on the exact cognitive mechanisms involved in mediating a link between 
perceiving a group as human and whether perceivers care about individuating them. Indeed "fungibility" is more of a description of the effect, than a mechanism by which it may operate. Instead, relying on the literature on individuation (and our own Study 3), it is likely that differential perceiver motivation plays a key role. Past research has shown that perceivers' motivation to individuate is sufficient to lead perceivers to generalize prior individuation experience (e.g., Hugenberg, et al., 2007). Indeed, in our prior studies, the humanlike and animallike stimuli are identical across conditions, and only perceivers' beliefs and motives about those stimuli differ. But exactly how might humanness trigger such motives? In the current work, we explored two non-mutually exclusive possibilities. First, such humanlike sophistication may enhance individuation motivation and performance because humanlike targets seem similar to the self, and second, perceiving targets as low in humanlike sophistication may make them seem more like outgroup members, thereby triggering outgroup homogeneity.

To the first of these, perceiving a target group as human may make it seem more similar to the self, thereby making the targets' unique identities seem important. Past work has indicated that people see themselves as more humanlike than their peers (Haslam, Bain, Douge, Lee, \& Bastian, 2005), and perhaps even prototypic of humanness. Further, the self is a highly salient and relevant stimulus, and garners more processing than non-self stimuli (e.g., Bargh, 1982; Tacikowski \& Ehrsson, 2016). Insofar as a group is made more human, and thereby seems more similar to the self, it may be afforded more motivated attention and processing. Thus, the extent to which perceivers consider mentally sophisticated individuals as similar to themselves may determine their motivation to individuate those targets.

Alternately, members of mentally unsophisticated groups may seem like outgroup members, triggering outgroup homogeneity. Indeed, outgroup homogeneity - the tendency to perceive outgroup members as similar to one another - is a well-established phenomenon (e.g. Quattrone \& Jones, 1980; Park \& Rothbart, 1982; Ostrom, Carpenter, Sedikides, \& Li, 1993). Insofar as a group is non-human, it may seem more like an outgroup (dissimilar from valued ingroups) and thereby trigger this outgroup homogeneity effect in which the similarities between the members of outgroups are exaggerated and the differences between them are minimized. 
Of interest in Study 6 is whether the effects of humanlike sophistication on individuation motivation are mediated by perceptions that a humanlike group is self-similar, perceptions that an animallike group is homogeneous, or both.

\section{Methods}

Participants. This study was designed to replicate and extend the results of Study 3. Thus, we relied again on the original power analysis, and adopted the same conservative target of 50 participants. In actuality, 58 mTurk workers $\left(M_{\mathrm{age}}=34.86, S D=10.60 ; 74.1 \%\right.$ White; $60.3 \%$ female $)$ participated in this study for $\$ 0.50$.

Procedure. The purpose of Study 6 was to replicate the effects of targets' mental sophistication on perceivers' motivation to individuate, and further to investigate whether this effect may be mediated by either perceptions that the more humanlike group is 1) more similar to the self and/or 2) seen as more heterogeneous than the more animallike group. To accomplish this, we used the alien anthropologist cover story used in Study 3 to manipulate the mental sophistication of the targets.

After reading these descriptions, all participants were asked to indicate for both Greebles and Animodes, in a randomized order, the extent to which "Greebles (Animodes) are similar to you" and the extent to which "Greebles (Animodes) are similar to one another," on 1 (Extremely Distinct) to 7 (Extremely Similar) Likert scales. These questions served as our measures of self-similarity and intragroup homogeneity. Finally, they indicated the extent to which they "would be interested in learning the unique identities of" the two species, on a 1 (Completely Uninterested) to 7 (Extremely Interested) Likert scale. After completing these scales, participants indicated which was the more advanced species as a manipulation check ${ }^{5}$, completed a demographics questionnaire, and were thanked and debriefed.

\section{Results and Discussion}

\footnotetext{
${ }^{5}$ Three participants failed the manipulation check. Excluding these participants does not change the overall pattern of results, and the meditation effect of Self-Similarity is descriptively stronger.
} 
Preliminary Analyses. Replicating Study 3, a paired samples t-test revealed that participants reported significantly more interest in individuating humanlike Greebles $(M=5.60, S D=1.757)$ than the animallike Animodes $(M=4.36, S D=1.944), t(44)=4.621, p<.001, d=0.669$.

Also, before testing the complete model, we tested the direct effect of our manipulation of mental sophistication on our proposed mediators by running two paired samples t-tests. Participants reported that Greebles $(M=5.47, S D=1.709)$ were more similar to the self than were Animodes $(M=2.62, S D=1.694)$, $t(57)=8.352, p<.001, d=1.675$. Likewise, participants reported that Greebles $(M=4.67, S D=1.572)$ were less similar to one another (less homogenous) than Animodes $(M=5.33, S D=1.560), t(57)=-2.331, p=.023$, $d=-0.421$.

Primary Analyses. In the primary tests of our two hypotheses, we ran separate within-subjects mediation models using Montoya and Hayes's (2017) MEMORE macro with 10,000 bootstraps. First, we tested whether Self-Similarity mediated the Mental Sophistication-to-Individuation Motivation relationship. Initially, Mental Sophistication significantly predicted Motivation to Individuate, $\beta=1.241$, $t(57)=4.621, p<.001$, and Self-Similarity, $\beta=2.845, t(57)=8.352, p<.001$, and when Self-Similarity was entered into the model, the indirect effect from Mental Sophistication to Self-Similarity and on to Motivation to Individuate was significant, $\beta=0.898,95 \% \mathrm{CI}[0.350,1.559]$. The direct effect of Mental Sophistication on Motivation to Individuate was no longer significant with Self-Similarity in the model, $\beta=0.344, t(57)=0.920, p=.361$. This finding shows that the Mental Sophistication-to-Motivation to Individuate link is mediated by perceived Self-Similarity.

Next, we tested whether Intragroup Homogeneity mediated the relationship between Mental Sophistication and Motivation to Individuate. As before, Mental Sophistication significantly predicted Motivation to Individuate, $\beta=1.241, t(57)=4.621, p<.001$, and Intragroup Homogeneity, $\beta=-0.655, t(57)=-$ 2.331, $p=.023$, and when Intragroup Homogeneity was entered, the indirect effect from Mental Sophistication to Intragroup Homogeneity and on to Motivation to Individuate was significant, $\beta=0.241$, 95\% CI[0.005,0.656]. The direct effect of Mental Sophistication on Motivation to Individuate, however, remained significant with Intragroup Homogeneity in the model, $\beta=1.000, t(57)=3.863, p<.001$. These 
findings show that the Mental Sophistication-to-Motivation to Individuate link can also be explained by changes in Intragroup Homogeneity.

Because both of these meditational paths were significant, we tested whether these processes can both be observed when a part of the same model. To test this, we entered both Self-Similarity and Intragroup Homogeneity into a single parallel mediation model. The parallel mediation analysis showed that the indirect path through Self-Similarity remained significant, $\beta=0.669,95 \% \mathrm{CI}[0.026,1.314]$, but the indirect path through Intragroup Homogeneity did not, $\beta=0.192,95 \% \mathrm{CI}[-0.002,0.593]$, suggesting that Self-Similarity may be the best explanation for the Mental Sophistication-to-Individuation Motivation link.

Taken together, Study 6 showed that, although both self-similarity and intragroup homogeneity statistically mediated the relationship between species' perceived sophistication and perceivers' motivation to individuate, the effects of self-similarity emerge above and beyond the effects of intragroup homogeneity. Put simply, perhaps the desire to see novel groups as variegated and consisting of unique individuals may stem from the perception that they are similar to the self (presumably a unique individual). However, it is important to note that although self-similarity appears to play an important role in the current effects, this is by no means and exhaustive test of potential mediators. Future research could benefit from considering other possible mechanisms. 


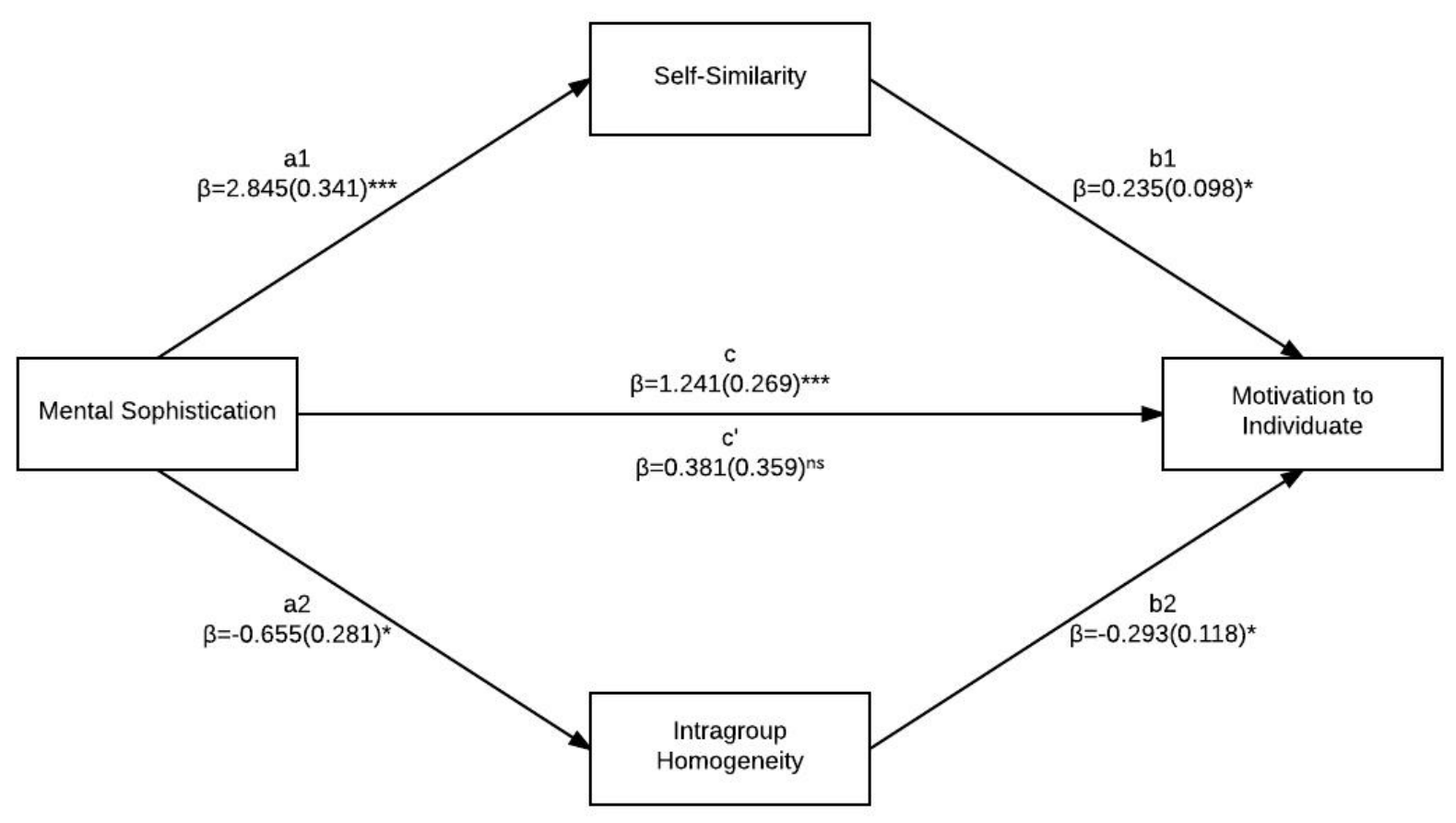

Significant Indirect Effect of Self Similarity, $\beta=0.669(0.316), 95 \% \mathrm{Cl}[0.026,1.314]$

Nonsignificant Indirect Effect of Intragroup Homogeneity, $\beta=0.192(0.154), 95 \% \mathrm{Cl}[-0.002,0.593]$

Figure 4. The parallel mediation model including self-similarity and intragroup homogeneity as mediators of the relationship between mental sophistication and participants' motivation to individuate.

Unstandardized regression coefficients are indicated and standard errors are presented in parentheses. $* p<.05, * * * p<.001$

\section{General Discussion}

Across six studies, we showed evidence that beliefs about the mental capacities of novel organisms were related to the individuation of those organisms (Study 1). But, it is not that as people learned to individuate, they ascribed the organisms more humanlike minds (Study 2). Rather, when these novel organisms were described as having more sophisticated humanlike, compared to simplistic animallike, mental characteristics, participants were more motivated to learn them (Study 3) and they were better learned (Studies 4 and 5). However, this effect was not simply that organisms with more humanlike minds were learned quicker or easier overall, rather, once participants had gained expertise 
differentiating between similar stimuli, this individuation skill was only translated to a new group of stimuli if that group had humanlike capacities (Study 5). Finally, we showed that beings with more sophisticated minds were perceived to be more similar to the self than beings with more simplistic minds, and that this increased similarity to the self led to increased motivation to individuate sophisticated beings above and beyond the effects of intragroup heterogeneity (Study 6).

The current research has interesting implications for the literatures on mind ascription and individuation. Perhaps most importantly, the current work extends the effects of mind ascription to learning and memory. To our knowledge, whereas much past research has focused on when minds are perceived and when they are not, no past research has demonstrated that perceiving minds influences how others are learned and discriminated from one another. As noted above, however, the effects are nuanced. It is not simply that more humanlike minds elicit better individuation, but rather that more humanlike minds elicit better generalization of prior individuation experience, in part because of the targets' similarity to the self.

This question of generalizing past experience in individuation is also a key question in the field of face memory. Indeed, some major models of face processing argue that motivation allows for latent expertise to be deployed, resulting in superior processing and memory for ingroup faces and other socially engaging targets (Hugenberg et al., 2010; Young \& Hugenberg, 2012). Given that the current work uses face-like stimuli (Greebles) that have been used in research on learning and generalizing individuation expertise, the present results make meaningful connections to this literature on individuation and perceptual skill.

Another important implication of the current work is that perceptions of self-similarity may play a key role in individuation. Indeed, although past research has shown that individuation of human faces is improved by a shared ingroup membership (Hugenberg et al., 2010), these results suggest that selfsimilarity may be an important part of this well-established effect. More generally, to the extent that another organism is similar to the self, that organism may seem more unique and warrant consideration of its individual identity. However, self-similarity (and intragroup homogeneity) is not necessarily the only 
possible mediating factor between humanlike faculties and individuation. One possible additional explanation is that groups that vary in mental ability may also appear to vary in entitativity (Hamilton \& Sherman, 1996). Insofar as the ingroup appears more entitative than an outgroup, perhaps this entitativity is a partial generator of the motivation to individuate. This could plausibly affect the individuation of humanlike and animallike novel groups, but is left untested in the current design. Another possibility is that perceptions of usefulness of other organisms' unique identities are important to individuation. Presumably, organisms with humanlike mental faculties have more relevant or useful minds, in terms of how they might affect the perceiver (positively or negatively) and whether they could be effective collaborators or competitors. Recent evidence might point to this possibility. Outside of this experimental context, humanlike minds are ascribed to those people who are important, either because they could be a source of social interaction or a source of harm, but this is presumably in anticipation of some future interaction (Khalid et al., 2016; see also Wilson, See, Bernstein, Hugenberg, \& Chartier, 2014). The absence of the possible future interaction with Greebles implies that this cannot be the case for Greeble learning. That being said, just as the prospect of future interaction elicits perceptions of humanity, perceiving humanity may prepare a person for interaction. Working to disentangle these and other alternative causal chains leading to processing differences is an important area of future inquiry.

\section{Future Directions.}

Although the current work has demonstrated a novel mind-to-individuation link, a number of important questions remain. For example, our manipulations have focused primarily on what differentiates humans from animals: agency, or the ability to self-regulate, plan, and think. However, this has in essence held the experience dimension of mind constant. Despite this, there is some evidence that perceptions of experience could also play a key role in individuation. In Studies 1 and 2, we found evidence that both agency and experience were related to individuation. Future research might benefit from considering how organisms that differ in experience (e.g., humans vs. automata) might also generate differential individuation motives. 
The current findings, which shed light on processes underlying mind perception and individuation, might also be extended to possibilities for future interventions aimed at improving intergroup relations. Given our findings that beliefs about the mental faculties of a group of organisms affect the individuation skill of that group, interventions aimed at improving individuation of outgroup members, for example, could focus on the sophisticated, humanlike mental faculties of that group and ways in which members of the outgroup are similar to the self. These types of interventions could be especially important considering past research has shown that understanding the variability within an outgroup leads to reduced prejudice and discrimination (Brauer \& Er-Rafiy, 2011). Future efforts testing the effects of such an intervention could prove to be greatly impactful to intergroup relations.

Finally, the current research builds upon past research in the perceptual learning domain, which has shown that associating objects with semantic content (i.e., making the objects meaningful) can improve visual discrimination of those objects (e.g., Gauthier, James, Curby, \& Tarr, 2003). In the current research, however, we find that not all semantic content is equal when learning to perceptually discriminate amongst novel stimuli. Indeed, only our humanlike semantic content improved subsequent learning. Thus, mere semantic content alone does not appear to be a sufficient explanation for the results. Future research may benefit from understanding how different semantic content may differentially influence perceivers' motivation to discriminate amongst novel stimuli.

\section{Conclusion.}

In closing, these studies have shown that, even after stripping away all perceptual cues of humanity, there is a connection between how we ascribe humanlike qualities to agents and how we learn the perceptual properties of those agents. Study 1 shows this via correlational evidence; the more participants imbue Greebles with experiential capacity and agency, the better they learn to individuate them. Study 3 provided initial evidence for the direction of this effect, showing that perceiving sophisticated mind leads to increased motivation to individuate. Study 4 supports this evidence, finding that learning to individuate Greebles is facilitated when they are presented as mentally humanlike, but not animallike and Study 5 shows that a generalization of preexisting individuation experience underlies this 
process, indicating that believing other entities are mentally humanlike activates latent perceptual skill that is otherwise not deployed for animallike entities. Finally, Study 6 shows that increased similarity to the self for mentally sophisticated Greebles leads to increased individuation motivation. In summary, these results show that perceiving other agents as humanlike in mind, and therefore similar to the self, facilitates the ability to learn them as unique individuals, whereas perceiving animallike minds in other agents makes them distinct from the self and unworthy of individuation. 


\section{References}

Bargh, J. A. (1982). Attention and automaticity in the processing of self-relevant information. Journal of Personality and Social Psychology, 43, 425.

Brauer, M., \& Er-Rafiy, A. (2011). Increasing perceived variability reduces prejudice and discrimination. Journal of Experimental Social Psychology, 47, 871-881.

Capozza, D., Falvo, R., Favara, I., \& Trifiletti, E. (2013). The relationship between direct and indirect cross-group friendships and outgroup humanization: Emotional and cognitive mediators. Testing, Psychometrics, Methodology in Applied Psychology, 20, 383-397.

Castano, E., \& Giner-Sorolla, R. (2006). Not quite human: Infrahumanization in response to collective responsibility for intergroup killing. Journal of Personality and Social Psychology, 90, 804.

Čehajić, S., Brown, R., \& González, R. (2009). What do I care? Perceived ingroup responsibility and dehumanization as predictors of empathy felt for the victim group. Group Processes \& Intergroup Relations, 12, 715-729.

Claypool, H. M., \& Bernstein, M. J. (2014). Social exclusion and stereotyping: Why and when exclusion fosters individuation of others. Journal of Personality and Social Psychology, 106, 571.

Cortes, B. P., Demoulin, S., Rodriguez, R. T., Rodriguez, A. P., \& Leyens, J. P. (2005). Infrahumanization or familiarity? Attribution of uniquely human emotions to the self, the ingroup, and the outgroup. Personality and Social Psychology Bulletin, 31, 243-253.

Curby, K. M., \& Gauthier, I. (2009). The temporal advantage for individuating objects of expertise: Perceptual expertise is an early riser. Journal of Vision, 9, 1-13.

Dennet, D. C. (1996). Kinds of minds: Towards an understanding of consciousness. New York, NY: Basic Books.

Deska, J. C., Almaraz, S. M., \& Hugenberg, K. (2017). Of mannequins and men: Judgments of animacy are bounded by perceptual and processing similarities to humans. Social Psychological and Personality Science, 8, 183-190. 
Epley, N., Akalis, S., Waytz, A., \& Cacioppo, J. T. (2008). Creating social connection through inferential reproduction loneliness and perceived agency in gadgets, gods, and greyhounds. Psychological Science, 19, 114-120.

Epley, N., Waytz, A., \& Cacioppo, J. T. (2007). On seeing human: A three-factor theory of anthropomorphism. Psychological Review, 114, 864-886.

Fiske, S. T., \& Neuberg, S. L. (1990). A continuum of impression formation, from category-based to individuating processes: Influences of information and motivation on attention and interpretation. Advances in Experimental Social Psychology, 23, 1-74.

Gauthier, I., James, T. W., Curby, K. M., \& Tarr, M. J. (2003). The influence of conceptual knowledge on visual discrimination. Cognitive Neuropsychology, 20, 507-523.

Gauthier, I., \& Tarr, M. J. (1997). Becoming a "Greeble” expert: Exploring mechanisms for face recognition. Vision Research, 37, 1673-1682.

Gauthier, I., \& Tarr, M. J. (2002). Unraveling mechanisms for expert object recognition: bridging brain activity and behavior. Journal of Experimental Psychology: Human Perception and Performance, 28, 431.

Gauthier, I., Tarr, M. J., Anderson, A. W., Skudlarski, P., \& Gore, J. C. (1999). Activation of the middle fusiform 'face area' increases with expertise in recognizing novel objects. Nature Neuroscience, 2, 568-573.

Gray, H. M., Gray, K., \& Wegner, D. M. (2007). Dimensions of mind perception. Science, 315, 619.

Hamilton, D. L., \& Sherman, S. J. (1996). Perceiving persons and groups. Psychological Review, 103, 336.

Haslam, N. (2006). Dehumanization: An integrative review. Personality and Social Psychology Review, 10, 252-264.

Haslam, N., Bain, P., Douge, L., Lee, M., \& Bastian, B. (2005). More human than you: Attributing humanness to self and others. Journal of Personality and Social Psychology, 89, 937. 
Haslam, N., \& Loughnan, S. (2014). Dehumanization and infrahumanization. Annual Review of Psychology, 65, 399-423.

Hugenberg, K., Miller, J., \& Claypool, H. M. (2007). Categorization and individuation in the cross-race recognition deficit: Toward a solution to an insidious problem. Journal of Experimental Social Psychology. 43, 334-340.

Hugenberg, K., Young, S. G., Bernstein, M. J., \& Sacco, D. F. (2010). The categorization-individuation model: An integrative account of the other-race recognition deficit. Psychological Review, 117, 1168-1187.

Hugenberg, K., Young, S., Rydell, R. J., Almaraz, S., Stanko, K. A., See, P. E., \& Wilson, J. P. (2016). The face of humanity: Configural face processing influences ascriptions of humanness. Social Psychological and Personality Science, 7, 167-175.

Khalid, S., Deska, J. D., \& Hugenberg, K. (2016). The eyes are the windows to the mind: Direct eye gaze triggers the ascription of others' minds. Personality and Social Psychology Bulletin, 42, 16661677.

Leyens, J. P., Demoulin, S., Vaes, J., Gaunt, R., \& Paladino, M. P. (2007). Infra-humanization: The wall of group differences. Social Issues and Policy Review, 1, 139-172.

Leyens, J. P., Paladino, P. M., Rodriguez-Torres, R., Vaes, J., Demoulin, S., Rodriguez-Perez, A., \& Gaunt, R. (2000). The emotional side of prejudice: The attribution of secondary emotions to ingroups and outgroups. Personality and Social Psychology Review, 4, 186-197.

Leyens, J. P., Rodriguez-Perez, A., Rodriguez-Torres, R., Gaunt, R., Paladino, M. P., Vaes, J., \& Demoulin, S. (2001). Psychological essentialism and the differential attribution of uniquely human emotions to ingroups and outgroups. European Journal of Social Psychology, 31, 395411.

Looser, C. E., \& Wheatley, T. (2010). The tipping point of animacy: How, when, and where we perceive life in a face. Psychological Science, 21, 1854-1862. 
Loughnan, S., Haslam, N., \& Bastian, B. (2010). The role of meat consumption in the denial of moral status and mind to meat animals. Appetite, 55, 156-159.

Mason, M. F., \& Macrae, C. N. (2004). Categorizing and individuating others: The neural substrates of person perception. Journal of Cognitive Neuroscience, 16, 1785-1795.

Montoya, A. K., \& Hayes, A. F. (2017). Two-condition within-participant statistical mediation analysis: A path-analytic framework. Psychological Methods, 22, 6.

Nussbaum, M. C. (1999). Sex and social justice. Oxford, England: Oxford University Press.

Ostrom, T. M., Carpenter, S. L., Sedikides, C., \& Li, F. (1993). Differential processing of in-group and out-group information. Journal of Personality and Social Psychology, 64, 21.

Park, B., \& Rothbart, M. (1982). Perception of out-group homogeneity and levels of social categorization: Memory for the subordinate attributes of in-group and out-group members. Journal of Personality and Social Psychology, 42, 1051.

Pauker, K., Weisbuch, M., Ambady, N., Sommers, S. R., \& Ivcevic, Z. (2009). Not so Black and White: Memory for ambiguous group members. Journal of Personality and Social Psychology, 96, 795810.

Pereira, C., Vala, J., \& Leyens, J. P. (2009). From infra-humanization to discrimination: The mediation of symbolic threat needs egalitarian norms. Journal of Experimental Social Psychology, 45, 336344.

Quattrone, G. A., \& Jones, E. E. (1980). The perception of variability within in-groups and out-groups: Implications for the law of small numbers. Journal of Personality and Social Psychology, 38, 141.

Scott, L. S., Tanaka, J. W., Sheinberg, D. L., \& Curran, T. (2008). The role of category learning in the acquisition and retention of perceptual expertise: A behavioral and neurophysiological study. Brain Research, 1210, 204-215. 
Tacikowski, P., \& Ehrsson, H. H. (2016). Preferential processing of self-relevant stimuli occurs mainly at the perceptual and conscious stages of information processing. Consciousness and Cognition, 41, 139-149.

Tanaka, J. (2001). Where are object properties? In the world or in the mind?. Behavioral and Brain Sciences. 24, 493-494.

Tarr, M. J., \& Gauthier, I. (2000). FFA: A flexible fusiform area for subordinate-level visual processing automatized by expertise. Nature Neuroscience, 3, 764-770.

Vaes, J., Bain, P. G., \& Leyens, J. P. (2014). Understanding humanness and dehumanization: Emerging themes and directions. In P. G. Bain, J. Vaes, \& J. P. Leyens (Eds.), Humanness and Dehumanization (pp. 323-336). New York: Psychology Press.

Vasiljevic, M., \& Viki, G. T. (2013). Dehumanization, moral disengagement and public attitudes to crime and punishment. Humanness and Dehumanization, 129-146.

Viki, G. T., Osgood, D., \& Phillips, S. (2013). Dehumanization and self-reported proclivity to torture prisoners of war. Journal of Experimental Social Psychology, 49, 325-328.

Waytz, A., Epley, N., \& Cacioppo, J. T. (2010). Social cognition unbound insights into anthropomorphism and dehumanization. Current Directions in Psychological Science, 19, 58-62.

Waytz, A., Gray, K., Epley, N., \& Wegner, D. M. (2010). Causes and consequences of mind perception. Trends in Cognitive Sciences, 14, 383-388.

Waytz, A., Heafner, J., \& Epley, N. (2014). The mind in the machine: Anthropomorphism increases trust in an autonomous vehicle. Journal of Experimental Social Psychology, 52, 113-117.

Wilson, J. P., See, P., Bernstein, M. J., Hugenberg, K., \& Chartier, C. (2014). Differences in anticipated interaction drive own group biases in face memory. PlosONE, 9, e90668.

Young, S. G., \& Hugenberg, K. (2012). Individuation motivation and face experience can operate jointly to produce the own-race bias. Social Psychological and Personality Science, 3, 80-87. 